\title{
Cloud Computing: Current Job Trends in Asia
}

\author{
Shikha Jain \\ Assistant Professor \\ Amity University \\ Noida
}

\author{
Neeru Chauhan \\ Assistant Professor \\ Amity University \\ Noida
}

\begin{abstract}
Cloud computing entrusts remote services with a user's data, software and computation. Added to this, cloud, innovation and entrepreneurship have a strong linkage. This linkage brings to the fore various dynamic changes in the perspective of organizations. Specifically, the change is visible and highly acceptable in every type of organization, country and businesses. The paper discusses the emerging field of cloud computing in three modules. Each module provides an insight to the rise of cloud related jobs. The first module gives a brief outlook to the changing trends of IT job market towards cloud computing. Second module outlines the skill set and certifications concerning cloud computing. This module highlights the types of cloud computing jobs as well. Final module provides the graphical description of growth and growing opportunities in cloud computing jobs in Asia including India.
\end{abstract}

\section{General Terms}

Cloud Computing Demand, Cloud Job Growth

\section{Keywords}

Job trends, business size, healthcare and education sectors.

\section{INTRODUCTION}

Cloud computing can be seen as an innovation in different ways. From a technological perspective it is an advancement of computing, applying virtualization concepts to utilize hardware more efficiently. Yet a different point of view is to look at cloud computing from an IT deployment perspective. In this sense cloud computing has the potential to revolutionize the way, how computing resources and applications are provided, breaking up traditional value chains and making room for new business models [1]. There were a number of dynamics involved in contributing to the evolution of Cloud Computing. Virtualization technologies, highbandwidth internet \& communication technologies, delivery of enterprise apps, software inter-operability standards, Web 2.0 were some of the key influencing factors for the emergence of the "CLOUD" world. In 1999, the face of Cloud Computing entered the corporate world with the introduction of SalesForce.com to deliver Enterprise Applications over the internet. This marked the beginning of Software As A Service (SaaS). In 2006, Infrastructure As A Service (IaaS) and Platform As A Service (PaaS) were introduced by Amazon's Elastic Compute Cloud (EC2) commercial web service. In 2009, Google \& Microsoft entered into the foray of offering enterprise application services [2]. The evolution of cloud computing can be split into 3 phases [3]:-

- The Idea Phase - this started in the 1960s and stretched to the pre internet bubble era. The core idea of computing as a utility computing and grid computing developed [3].
- The Pre Cloud Phase - this started around 1999 and lasted till 2006. In this phase internet as the mechanism to provide Application as Service got developed [3].

- The Cloud Phase - this phase started in 2007 when the term cloud computing became popular and the sub classification of IaaS, PaaS \& SaaS got formalized [3].

Cloud computing has a lot in store in terms of future job creation. It is anticipated that cloud computing will lead to a generation of an estimated 14 million novel job opportunities across the world in the span of the coming three years. The scope of the fresh jobs may extend beyond the IT sector. The estimates are an outcome of research carried out by IDC funded by the Microsoft Corporation. It is worth to note that only 1.18 million of the anticipated lot of 14 million jobs will be hosted in the North America region. A hefty 10 million of the jobs will arise in the Asia Pacific region, India and China. The primary reason for this remains the mammoth size of the region's human resource pool - about 1.3 promising personnel in India and China alone, as per findings of the report [4]

\section{TYPES OF JOBS IN CLOUD}

There are numerous jobs in cloud ranging from Java Developer to Technical Architect to Linux Engineer and Web Developer. The list of Cloud jobs with the description of few of them[5] are as follows:-Architect,Developer,Solutions Architect, Java Developer, Consultant ,Senior Developer, Senior Architect, Administrator, Systems Engineer ,Technical Architect, Linux Engineer, Systems Administrator ,Web Developer, Linux Administrator, Technical Leader ,Product Manager, Applications Developer, Network Consultant, Enterprise Architect, PHP Developer, Database Specialists[6], System Specialist [6], Security Specialist [6], Operations Specialist [6].

\subsection{Cloud architects}

Focus on turning the configuration of the cloud-based systems and solutions into something that meets the business requirements [6].

\subsection{Cloud developers}

Focus on the configuration and development of the cloudbased systems, including coding within the specific target PaaS or IaaS cloud platforms, with deep knowledge as to how those platforms function [6].

\subsection{Cloud database specialist}

Focus on the use of cloud-based database systems, and how they interact with cloud-based or legacy systems [6]. 


\subsection{Cloud System Quality Specialist}

Focus on testing migrated or developed cloud-based systems to insure that they live up to business and quality expectations [6].

\subsection{Cloud Security Specialist}

Focus on the proper way to secure information existing within cloud-based systems [6].

\subsection{Cloud Operations Specialist}

Focus on the operations of the cloud-based systems, including monitoring and active governance of those systems [6].

\section{SKILLSET OF CLOUD EXPERT}

Cloud platform is a new architecture the underlying technologies for its usage already exist. The skill sets required for few jobs in Cloud computing [7] are:-For Cloud Architect (enterprise networking, security and virtualization aspects [7]), For Cloud Security Expert (virtualization, security of data/network aspects).

\section{CERTIFICATIONS}

\subsection{Certificate of Cloud Security Knowledge}

- Host is Cloud Security Alliance.

- Most prestigious Cloud Computing Certification.

- Certification on Cloud Computing Security [8].

\subsection{CloudU Certificate}

- Host is Rackspace.

- Best Certification Program available on Cloud Computing Fundamentals [8].

\subsection{IBM Certified Solution Advisor-Cloud Computing Architecture \\ - Host is IBM. \\ - Covers Cloud Computing Basics and IBM offerings [8]}

\subsection{IBM Certified Solution Architect-Cloud Computing Infrastructure}

- Host is IBM.

- Targets IBM Cloud Computing Reference Architecture [8].

\subsection{Google Apps Certified Deployment} Specialist

- Host is Google

- Google's first Cloud Specialist Certification.

- Covers fundamentals of Google Apps for Business [8].

\subsection{Certified Force.com Developer}

- Host is Salesforce.com.

- Best Cloud Application Development Certification.

- Specific to Force.com Platform [8].

\subsection{Salesforce.com Certified Administrator}

- Host is Salesforce.com.

- Vital Certification for administrators of Salesforce.com.
- Covers Sales and Service Clouds [8].

\subsection{VMware Certified Professional (VCP)}

- Host is VMware

- Most popular Virtualization Certification.

- Includes coverage of vSphere's role in cloud Architecture [8].

\subsection{CompTIA Essentials}

- Host is CompTIA

- Covers basic concepts for IT and Business Personnel [8].

\subsection{Certified Cloud Professional (CCP)}

- Host is Arcitura.

- Covers Cloud Computing Basics [8].

\section{ANALYSIS}

The analysis section includes three sub parts. Each part provides an insight to the cloud computing job growth over the past few years. The graphical description is used to show the analysis in all three parts.

\subsection{Sector wise growth}

Microsoft-sponsored IDC research study demonstrates that worldwide, nearly 1.6 million jobs will be created across the education, healthcare and government verticals as a result of cloud computing by the end of 2015[9]. Slated for release on Monday, March 5, the research tells us that cloud computing goes beyond business cost-savings and has the potential to restore economic health within organizations and globally. It describes the cloud computing job growth in sectors like healthcare, government and education of Asia. Communication and media sector will be the fastest growing sector in Asia, with 1.8 million cloud related jobs by 2015 , representating a $103 \%$ increase compared to 2012.Discrete manufacturing in Asia will have $880 \mathrm{~K}$ new cloud jobs created by 2015.By 2015 , the government sector will have a total of $315 \mathrm{~K}$ new jobs created from the cloud, an increase of $72 \%$ since 2012 .The graphs are created from the data provided by the Microsoft IDC report [9]

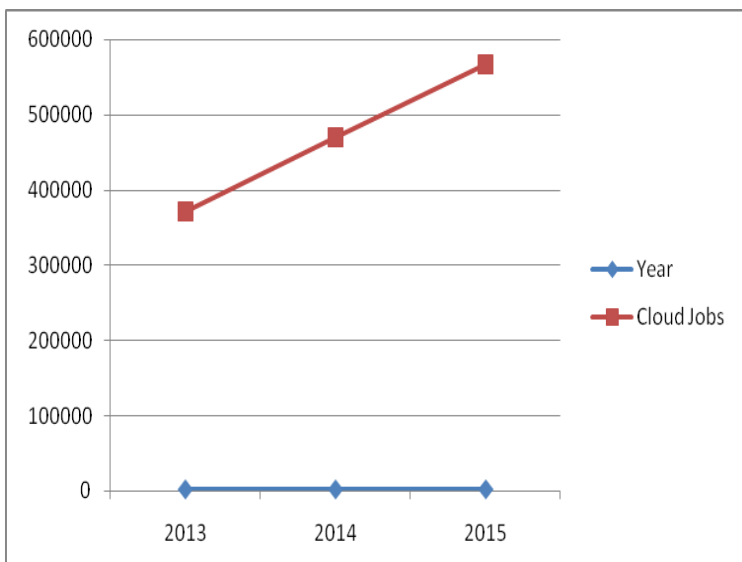

Fig 1: Cloud job growth in education sector(2013-2015) 


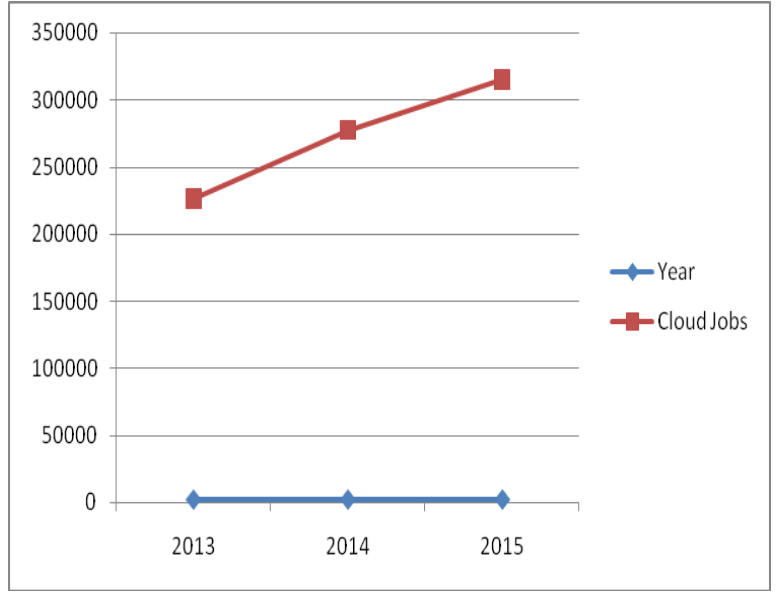

Fig 2: Cloud job growth in government sector(2013-2015)

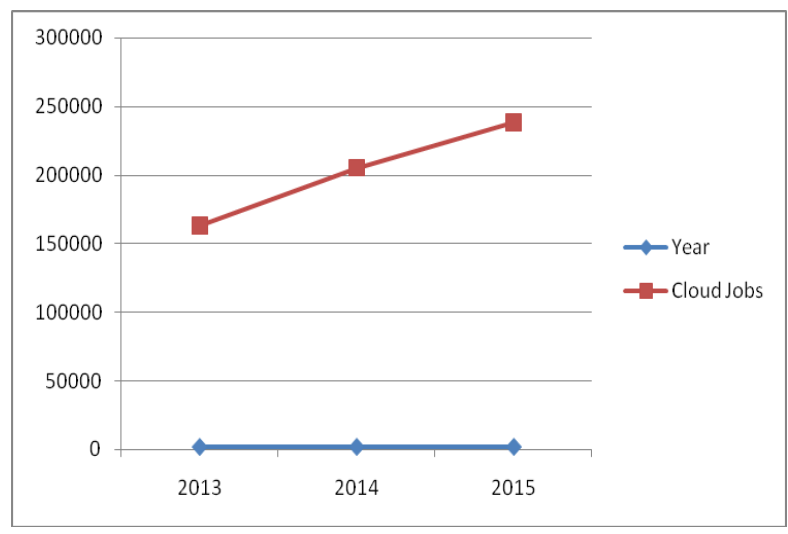

Fig 3: Cloud job growth in healthcare sector(2013-2015)

\subsection{Asia Specific Countries: Cloud Job Growth from 2012-2015}

Cloud related jobs by selected countries including public, private and hybrid jobs. The following conclusions can be made from the survey conducted by Microsoft[10]:-Japan is the nation with the largest percentage growth in cloud computing jobs by 2015: $155 \%$, China will add 4 million cloud related jobs by 2015 , which represents an increase by $84 \%$,China, India , Indonesia will add more than 7 million cloud related jobs by 2015,India and Indonesia nations with the highest unemployment rates will show a growth in cloud related jobs by $98 \%$ and $102 \%$ respectively between 2012 and 2015.

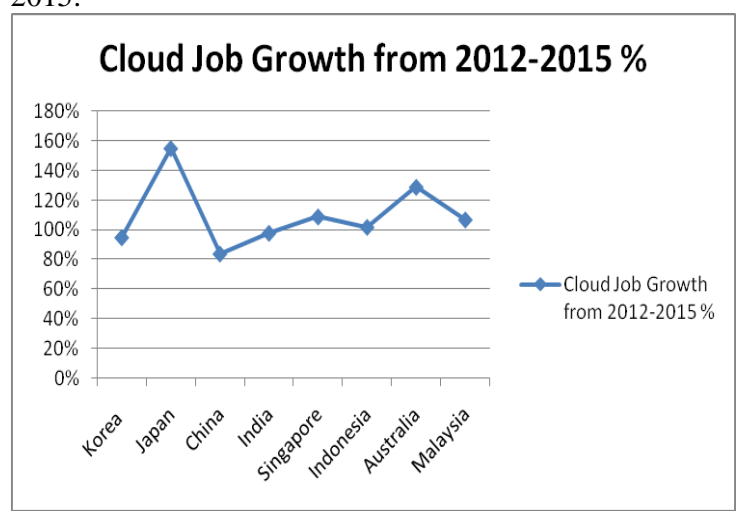

Fig 4: Cloud job growth in Asia specific countries

\subsection{Business Size Specific}

Cloud-related jobs offered by SMEs (under 500 employees) in Asia will achieve a compound annual growth rate (CAGR) of $28 \%, 2.2 \%$ higher than large enterprises (above 500 employees) with a $25.8 \%$ growth rate [11].

\subsubsection{Small-medium size Business}

Even now SME's have realized the potential of cloud computing as well. As a result, these organizations are making a shift to the cloud computing environment. Few reasons which are responsible for fast adoption of cloud environment by SME's are:-Reduced Capex \& Opex Costs ,Pay As You Go, On-Demand, Scalable Storage Options, Remote Access ,Green Computing, Ease of Implementation, Skilled Vendors, Response time, Even playing field for small start ups ,Performance, durability \& high availability[12].

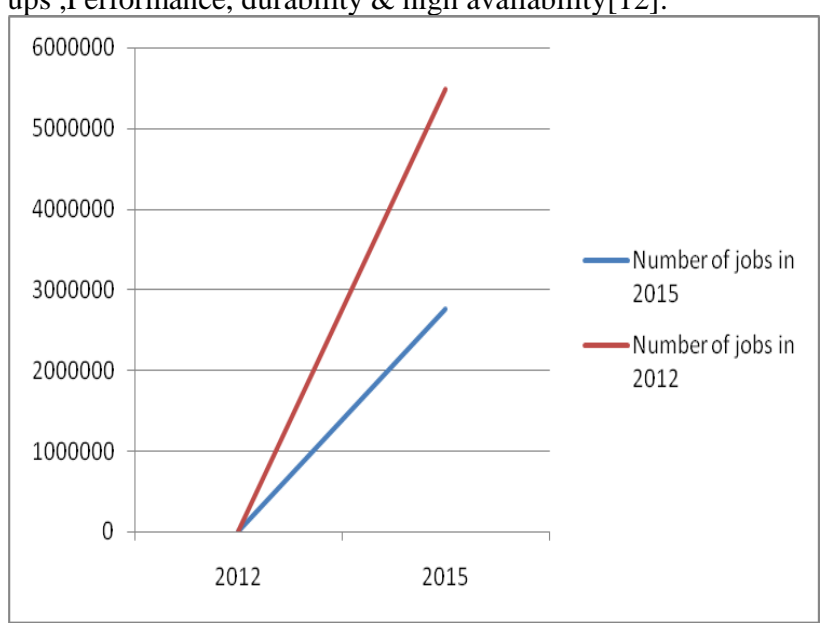

Fig 5 : Cloud job growth in SME from 2012 to 2015

\subsubsection{Enterprise Business}

The enterprises around the world are leveraging cloud computing technology, services and solutions to accelerate business agility [13].

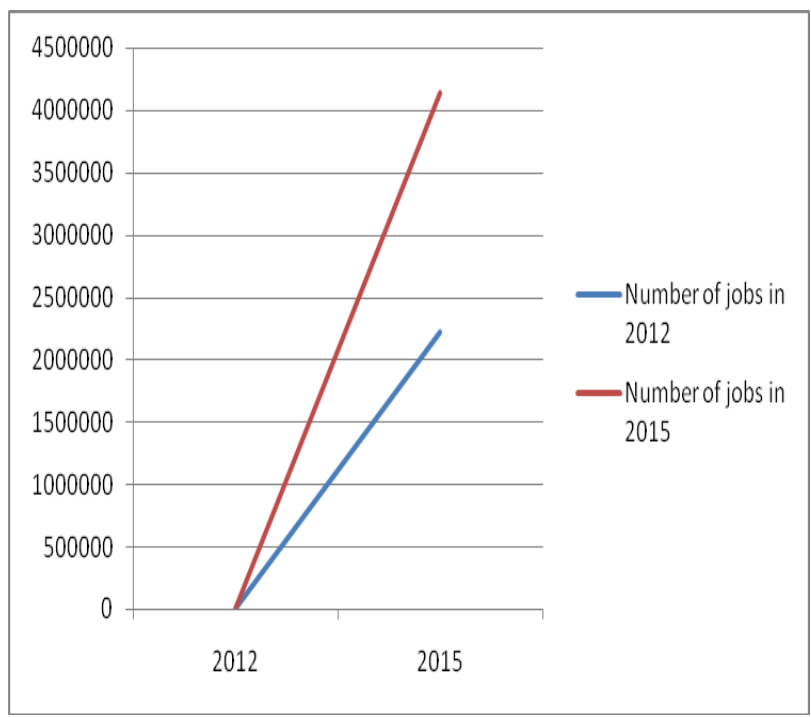

Fig 6: Cloud job growth in Enterprise from 2012 to 2015

These organizations are shifting towards this technology due to reduced cost, accelerate time to market, change in 
interaction with suppliers and customers, greater transparency on transactions, change in business model etc [14].

\section{CONCLUSION}

The central importance of this analysis is the intensive use of cloud yields several benefits like productivity benefits, enhancement in services provided to a large customer base, increased sophistication of organization, improvised focus on key business activities, reduction in time for establishing infrastructures etc.These beneficial factors are almost present and effecting every sector like IT, education, government ,media, healthcare. Therefore, it can be concluded that rapid adoption of this technology has yielded several jobs of several types as well. It can also be stated that cloud computing implementation is not limited to a certain specific field or region only.

\section{REFERENCES}

[1] Markus Bohm, Stefanie Leimeister, Christoph Riedi, Helmut Krchmar,Technische Universitat Munchen (TUM), Germany, Cloud Computing and Computing Evolution

[2] Deven Shah 2011 Cloud-n-More How did Cloud Computing Evolve?

[3] Udayan Banerjee 2011 The Evolution of Cloud Computing

[4] Humayun 2012 Cloud Computing Certification and Future Job Opportunities
[5] Cloud Computing Jobs Retrieved from http://www.itjobswatch.co.uk/jobs/uk/cloud\%20computi ng.do

[6] Joe McKendrick 2013. 6 Technology Jobs with a Cloud Twist.

[7] Rahul Shah, Isha Gakhar 2009 Careers in Cloud Computing

[8] Glen Roberts 2011, Top 10 Cloud Computing Certifications.

[9] Steve Aylward,General Manager, US Commercial Health and Life Sciences 2012, Cloud Computing's Role in Job Creation.

[10] IDC White Paper Sponsored by Microsoft Cloud Computing's Role in Job Creation, February 2012.

[11] Computerworld Hong Kong staff 2012, Microsoft : Cloud to create 9.62 million jobs in APAC

[12] How SME's Can Benefit Big From 'Cloud' Computing (And Why They Are Not) Retrieved from http://www.datanet.co.uk/smesbenefitfromcloud.aspx.

[13] Dennis McCafferty 2013, Enterprises slowly Adopting Cloud Computing

[14] Dr. Joe Graco, March 28, 2012,Industry Trends: How Enterprises are adopting Cloud Computing, IAOP Seminar, California Chapter Retrieved from http://www.iaop.org/FirmBuilder/Articles 